\title{
Struktur Hasil Translokasi Bangunan Vernakular Jawa Timur di Kampoeng Djawi Wonosalam
}

\author{
Yohanes Vincent Mahendar Bagaskara' ${ }^{1}$ dan Yusfan Adeputera Yusran² \\ 1, 2Jurusan Arsitektur, Fakultas Teknik, Universitas Brawijaya \\ ${ }^{1}$ vincentbagaskara@gmail.com; ${ }^{2} y u s f a n @ u b . a c . i d$
}

\begin{abstract}
ABSTRAK
Bangunan vernakular di Indonesia, khususnya bangunan vernakular Jawa Timur seiring waktu semakin berkurang. Banyak upaya yang dilakukan untuk mempertahankan eksistensi bangunan vernakular, salah satunya pelestarian secara eks-situ dengan penggunaan secara adaptif sebagai destinasi wisata seperti yang ditemukan di Kampoeng Djawi Wonosalam. Pemindahan bangunan vernakular ke lokasi baru dan fungsi yang baru menyebabkan perubahan pada bangunan vernakular, utamanya pada strukturnya. Perubahan yang terjadi sebagai bentuk penyesuaian terhadap lokasi baru dan aktivitas baru yang akan diwadahi. Tujuan dari penelitian ini adalah untuk menemukan perubahan struktur pada bangunan hasil translokasi. Metode deskriptif kualitatif digunakan untuk menemukan perubahan struktur yang terjadi, sehingga hasil yang didapat merupakan fakta kejadian sebenarnya. Perubahan yang terjadi dihubungkan dengan konsep adaptif bangunan eksoskeleton. Berdasarkan hasil pengamatan dan analisis, perubahan yang terjadi pada bangunan hasil translokasi disebabkan oleh faktor ketahanan, keamanan, visual dan pemenuhan aktivitas baru.
\end{abstract}

Kata kunci: translokasi bangunan vernakular, konservasi eks-situ, penggunaan adaptif

\section{ABSTRACT}

Vernacular buildings in Indonesia, especially vernacular buildings of East Java, are increasingly diminishing. Many efforts have been made to maintain the existence of vernacular buildings, one of which is ex-situ conservation by re-using it adaptively as a tourist destination as found in Kampoeng Djawi Wonosalam. Translocation of vernacular buildings to new locations and new function causes changes in vernacular buildings, particularly in its structure. Changes occur as an adaption to new locations and new activities that will be accommodated. The objective of this paper is to describe the structural changes in vernacular buildings as the result of translocation. Qualitative descriptive method is used to find the structural changes, so the results obtained are actual facts. Changes that occur then analyzed with the concept of adaptive exoskeleton building. According to the results of observations and analysis, changes that occur in vernacular building translocation are caused by resilience, safety, and visual factors, as well as fulfillment of new activities.

Keywords: vernacular building translocation, ex-situ conservation, adaptive reuse

\section{Pendahuluan}

Rapoport (1969) menyatakan bahwa bentuk rumah tidak hanya berupa fisik melainkan juga berfungsi sebagai implikasi faktor sosio-budaya. Di Indonesia bangunan yang berfungsi sebagai implikasi faktor sosio-budaya disebut bangunan vernakular. Bangunan vernakular telah mengarungi rentang waktu yang panjang dan telah teruji dalam laboratorium alam, sehingga memiliki nilai dan makna yang tak tertulis sebagai 
bagian dari budaya bangsa Indonesia. Saat ini jumlah bangunan vernakular semakin berkurang, hal itu disebabkan bahan baku yang semakin langka, perawatan yang relatif mahal, masuknya bahan bangunan baru yang lebih mudah didapat dan mudah dalam perawatannya, serta pengetahuan yang kurang tentang struktur dan konstruksi bangunan vernakular. Pelestarian perlu dilakukan karena bangunan vernakular Jawa memiliki bentuk dan struktur yang khas (Prijotomo, 2005).

Banyak upaya yang dilakukan untuk menjaga eksistensi bangunan vernakular, salah satunya adalah dengan memindahkan (translokasi) bangunan vernakular sekaligus mengembangkan potensinya menjadi destinasi wisata melalui pendekatan penggunaan kembali secara adaptif (adaptive reuse). Pelestarian ini dapat didefinisikan sebagai pelestarian bangunan vernakular secara eks-situ (Yusran, 2018). Penerapan konsep ini dapat dijumpai di Kampoeng Djawi Wonosalam. Konsep adaptive building exoskeleton yang dikemukakan oleh Scuderi (2015) menyatakan bahwa perubahan bangunan vernakular dari bentuk aslinya masih dapat dikatakan sebagai pelestarian.

Bangunan vernakular yang ditranslokasikan secara umum masih serupa dengan aslinya, namun mengalami beberapa perubahan. Salah satu perubahan yang teridentifikasi adalah fisik bangunan (struktur). Perubahan struktur bangunan vernakular ini merupakan tanggapan agar bangunan vernakular tersebut dapat berdiri pada lingkungan yang baru serta menampung aktivitas baru di dalamnya. Perubahan struktur yang dilakukan tetap mengacu pada proporsi dan bentuk dari bangunan aslinya. Hal tersebut menjadikan rupa dari bangunan ini masih menyerupai bangunan aslinya.

Berdasarkan pemaparan di atas, fenomena tentang perubahan struktur pada hasil translokasi bangunan vernakular di Kampoeng Djawi Wonosalam ini diangkat menjadi topik dalam penelitian ini. Perubahan yang terjadi kemudian dihubungkan dengan strategi perubahan yang dikemukakan oleh Scuderi. Melihat indikasi pelestarian eks-situ dari bangunan vernakular Jawa Timur di Kampoeng Djawi, penelitian ini berupaya untuk mendeskripsikan perubahan struktur yang terjadi akibat proses translokasi tersebut.

\section{Metode}

Metode yang digunakan dalam mengamati dan menganalisis perubahan struktur yang terjadi pada bangunan vernakular Jawa Timur hasil translokasi adalah deskriptif kualitatif. Deskriptif kualitatif digunakan untuk mengetahui suatu hal dengan keadaan lain yang memberi pengaruh dan memperkaya informasi pada perubahan struktur bangunan vernakular Jawa Timur hasil translokasi. Adapun tujuan dari penelitian ini untuk mengungkapkan kejadian, variabel dan keadaan yang terjadi saat penelitian berlangsung dengan menyuguhkan apa yang sebenarnya terjadi (fakta).

Pada tahap awal penelitian dilakukan wawancara dan studi pustaka untuk mengetahui gambaran tentang bangunan venakular Jawa Timur. Adapun variabel yang digunakan dalam penelitian ini difokuskan pada sistem struktur, elemen struktur dan material yang digunakan. Setelah itu, dilakukan pengamatan lapangan dan selanjutnya menguraikan permasalahan yang ada sesuai dengan kajian teori yang digunakan. Datadata perubahan struktur tersebut kemudian ditabulasikan dan dikaitkan dengan konsep adaptive reuse, dalam hal ini konsep adaptive building exoskeleton oleh Scuderi (2015).

Penentuan objek yang dikaji di Kampoeng Djawi Wonosalam difokuskan pada bangunan vernakular Jawa Timur yang ditranslokasi dan difungsikan sebagai penginapan. Menurut hasil wawancara awal dengan pemilik Kampoeng Djawi Wonosalam, di Kampoeng Djawi terdapat 4 jenis bentuk bangunan vernakular yang digunakan sebagai penginapan yaitu Griya Dorogepak, Griya Jineman, Griya Majapahit dan Griya Joglo. Jenis bentuk bangunan vernakular tersebut dikategorikan sendiri oleh Rudy Ermawan selaku pemilik Kampoeng Djawi Wonosalam. Bangunan vernakular yang ditranslokasi terdiri dari 5 (lima) bangunan vernakular dari 3 (tiga) jenis bentuk 
bangunan Jawa. Jenis yang pertama adalah Griya Dorogepak dengan 2 (dua) banguan, jenis Griya Jineman dengan 2 (dua) bangunan dan Griya Joglo dengan 1 (satu) bangunan. Jenis Griya Majapahit tidak masuk dalam objek yang diteliti karena bukan merupakan bangunan vernakular Jawa Timur yang ditranslokasikan.

Tabel 1. Strategi Perubahan Adaptive Building Exoskeleton menurut Scuderi (2015)

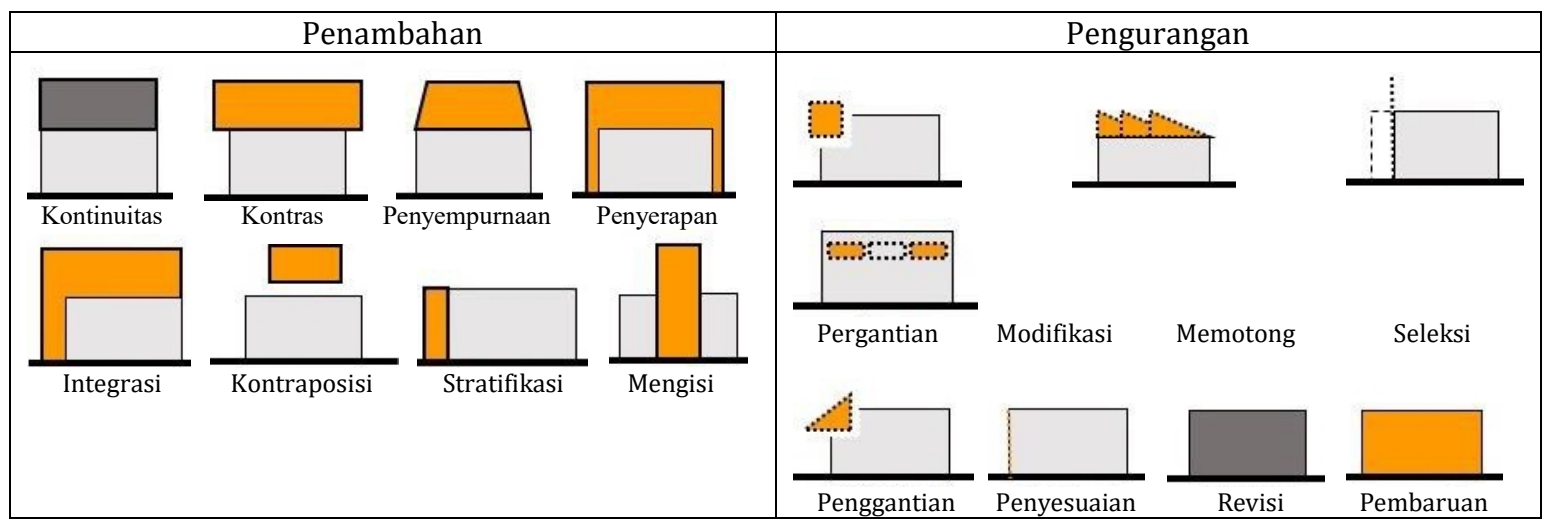

(Sumber: Scuderi, 2015)

\section{Hasil dan Pembahasan}

\subsection{Gambaran Umum Kampoeng Djawi}

Penelitian ini mengambil lokasi di Kampoeng Djawi, terletak di Dusun Gondang Desa Carangwulung Kecamatan Wonosalam, Kabupaten Jombang, Jawa Timur. Awalnya kawasan ini memiliki luas kurang lebih 1,3 hektar dan merupakan perkebunan berkontur curam dengan satu tempat tinggal. Kampoeng Djawi mulai dikembangkan menjadi destinasi wisata sejak tahun 2010 hingga sekarang. Setelah dilakukan pengembangan, luasnya berkurang menjadi 0,9 hektar.

Kampoeng Djawi pada awalnya dikembangkan sebagai tempat wisata untuk mengadakan kegiatan outbond hingga saat ini sudah menjadi kawasan wisata yang dapat digunakan sebagai tempat training, kegiatan outbond, penginapan, bahkan digunakan untuk kegiatan pemotretan. Pembangunan dilakukan oleh pemiliknya Rudy secara bertahap, dimulai dari mendatangkan bangunan vernakular untuk tempat beristirahat hingga menambahkan bangunan lainnya untuk mendukung kegiatan di Kampoeng Djawi. Rudy memilih menggunakan bangunan vernakular Jawa khususnya Jawa Timur karena ketertarikannya dengan arsitektur Jawa. Bangunan vernakular Jawa Timur yang digunakan berasal dari Nganjuk, Pasuruan, Mojokerto, Lamongan, Jombang dan sekitarnya. 

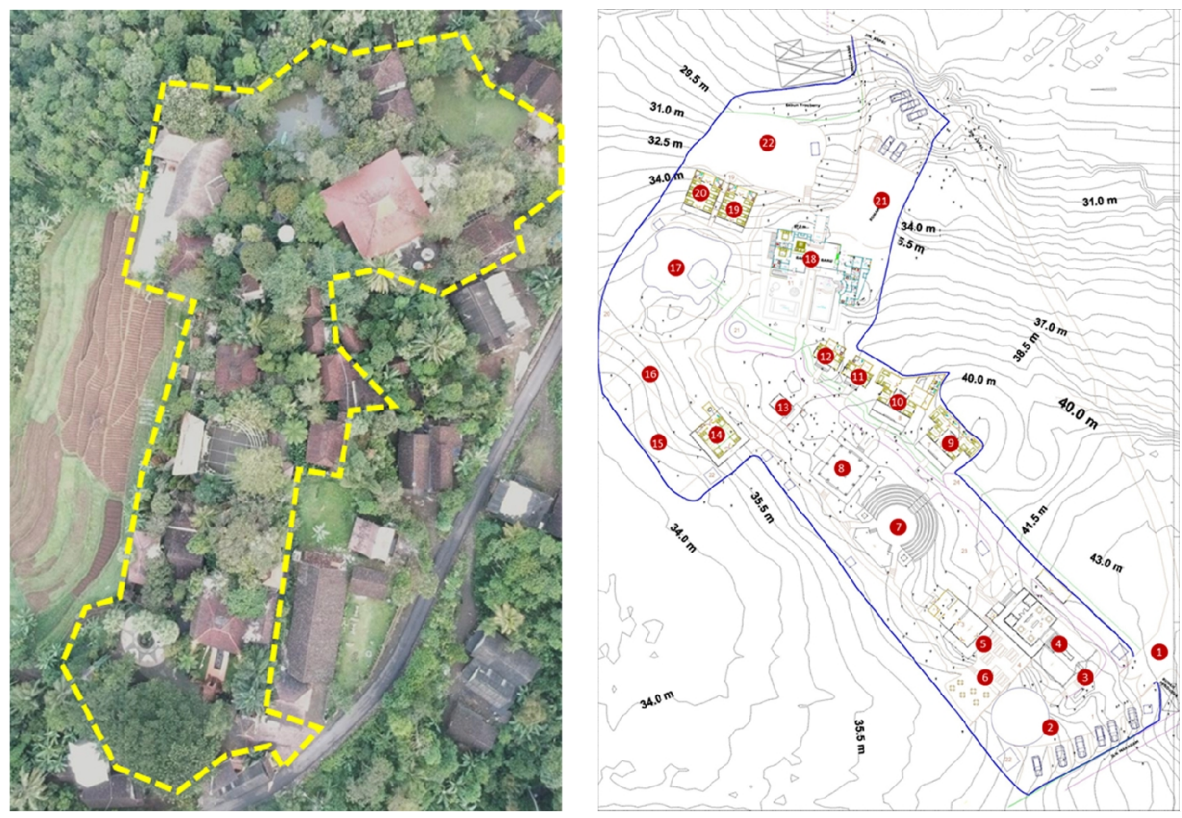

1. Main Entrance

2. Area Parkir

. Gapura

4. Front Office

5. Pawon

(Dapur/Resto)

6. Area Meja Makan

7. Amphiteather

8. Pendopo

9. Griya Dorogepak 1

10. Griya Dorogepak 2

11. Griya Majapahit 1

12. Griya Majapahit 2

13. Langgar

14. Griya Joglo

15. Kolam Renang

16. Griya Brawijaya

17. Danau Buatan

18. Balairung

19. Griya Jineman 1

20. Griya Jineman 2

21. Gallery (rencana)

22. Camping Ground

Gambar 1. Kawasan Kampoeng Djawi Wonosalam

Bangunan yang terdapat di Kampoeng Djawi Wonosalam terdiri dari bangunan vernakular Jawa Timur hasil translokasi dan bangunan modern dengan tampilan menyerupai bangunan vernakular Jawa. Bangunan vernakular yang ditranslokasikan digunakan sebagai penginapan, kantor, restoran dan pendapa. Griya Dorogepak merupakan bangunan translokasi yang pertama. Setelah pembangunan Griya Dorogepak 1 dan 2 selesai, bangunan berikutnya yang ditranslokasikan adalah front office, pawon, pendapa, Griya Joglo dan bangunan terakhir yang ditranslokasikan adalah Griya Jineman 1 dan 2. Bangunan modern yang dibangun difungsikan sebagai sebagai bangunan penunjang kegiatan di Kampoeng Djawi Wonosalam. Bangunan modern yang dibangun berupa cafe, tempat tinggal Rudy, Balairung (aula), dan penginapan berupa Griya Majapahit dan Griya Brawijaya. Semua bangunan moderen yang dibangun tetap berpatokan dan menggunakan gaya arsitektur Jawa.

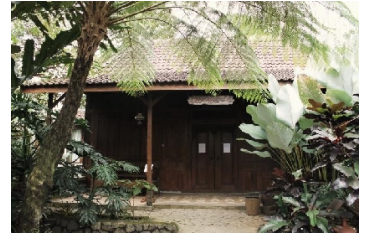

Griya Dorogepak 1

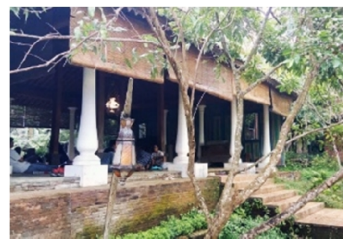

Pendapa

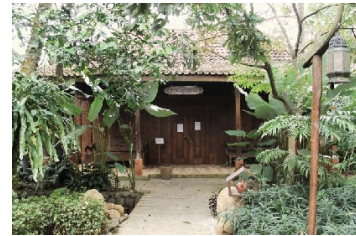

Griya Dorogepak 2

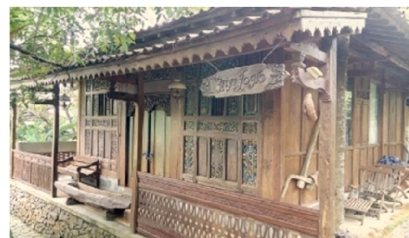

Griya Joglo

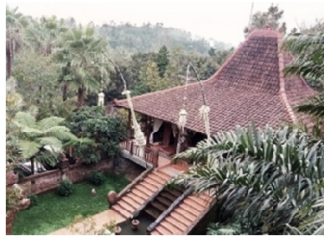

Front Office

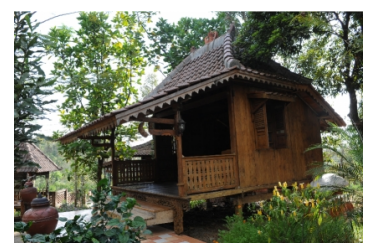

Langgar

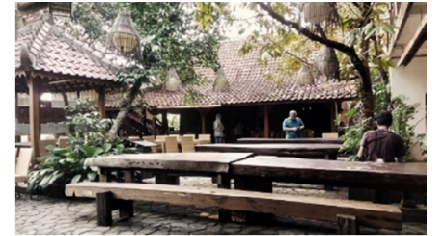

Pawon

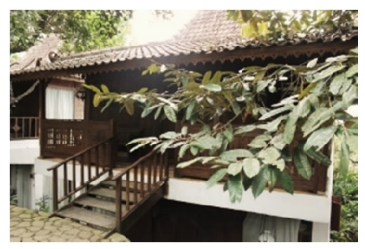

Griya Jineman

Gambar 2. Bangunan Hasil Translokasi di Kampoeng Djawi Wonosalam

\subsection{Translokasi Bangunan Vernakular}

Bangunan vernakular yang ditranslokasikan ke Kampoeng Djawi Wonosalam merupakan bangunan vernakular yang dibeli oleh Rudy dari pemilik sebelumnya 
maupun dari pengepul. Rudy menugaskan orang kepercayaannya untuk mencari bangunan tersebut. Setelah bangunan yang diinginkan didapat, Rudy menugaskan orang kepercayaannya tersebut untuk survei dan memeriksa bangunan tersebut apakah masih dapat ditranslokasikan atau tidak. Apabila bangunan dinyatakan layak untuk ditranslokasi, Rudy kemudian melakukan negosiasi untuk mendapatkan bangunan tersebut. Pembongkaran dan perakitan kembali dipimpin oleh Kusnairi selaku kepala tukang. Sebelum membangun kembali bangunan vernakular yang didapat, perlu terlebih dahulu melakukan pengolahan tanah di lokasi bangunan tersebut akan didirikan. Berikutnya Rudy dibantu oleh Kusnairi merencanakan pondasi, penguatan, pengawetan dan pencegahan terhadap rayap hingga memodifikasi beberapa bagian yang disesuaikan dengan aktivitas baru yang akan diwadahi.

\subsubsection{Griya Dorogepak}

Griya Dorogepak merupakan bangunan vernakular Jawa tipe limasan. Griya Dorogepak 1 berada pada sisi utara Griya Dorogepak 2. Bangunan yang digunakan untuk membangun Griya Dorogepak 1 dan 2 berjumlah tiga bangunan. Satu bangunan berasal dari Kecamatan Mojoagung Kabupaten Jombang dan dua bangunan berasal dari Mojokerto. Ketiga bangunan ini didapatkan langsung dari pemilik sebelumnya. Terdapat dua bangunan utama yang nantinya akan dijadikan penginapan, dalam hal ini adalah Griya Dorogepak 1 dan Griya Dorogepak 2. Satu bangunan yang lain digunakan untuk melengkapi kekurangan apabila di kedua bangunan tersebut terdapat bagian yang tidak dapat digunakan kembali. Secara umum struktur utama dari kedua bangunan utama yang akan dibangun memiliki struktur yang masih baik, sehingga hanya perlu mengganti beberapa bagian yang mulai rusak.

Perubahan yang jelas terlihat dari Griya Dorogepak 1 dan 2 adalah penambahan ruangan. Penambahan ruang dimaksudkan untuk mewadahi pengunjung yang banyak, serta fasilitas servis bagi pengunjung. Penambahan ruang yang terjadi di Griya Dorogepak 1 dan 2 merupakan penambahan yang ruang paling banyak dibandingkan dengan penginapan yang lainnya. Perubahan lainnya adalah penambahan pondasi, penambahan penguat, penggantian penguat, penggantian plafon, penambahan seng, penggantian genteng dan penambahan struktur beton. Tata ruang asli juga berubah karena penyesuaian lahan dan aktivitas baru. Begitupula luasan bangunan berubah karena mengalami penambahan dan perluasan.

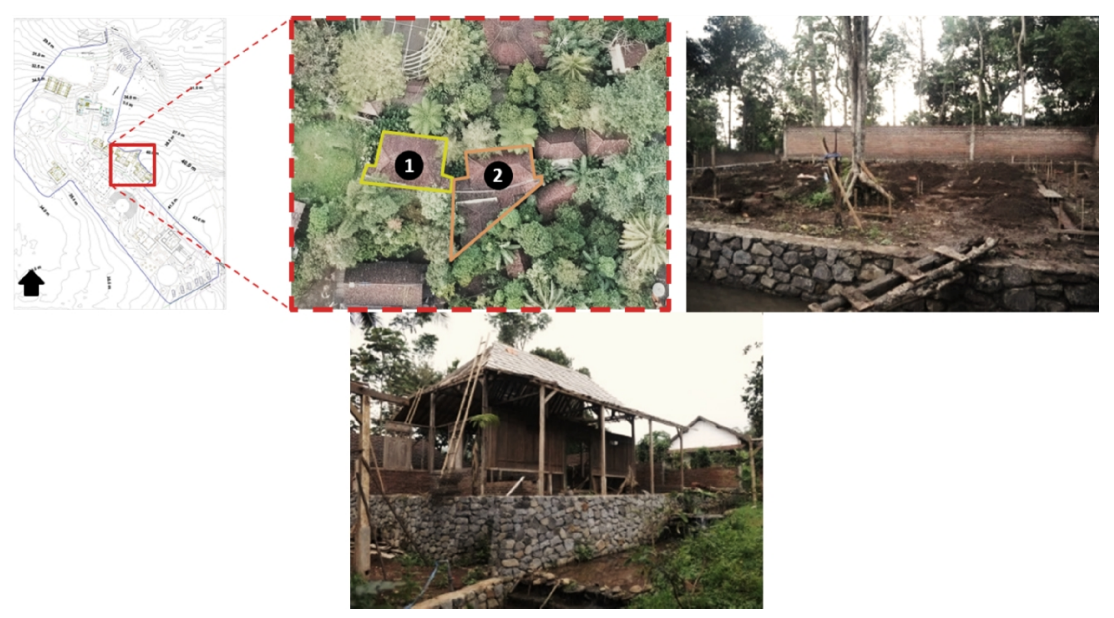

Gambar 3. Translokasi Griya Dorogepak 1 


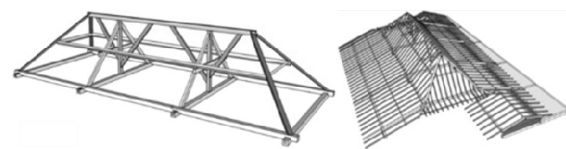

Struktur Atap Utama dan Tambahan

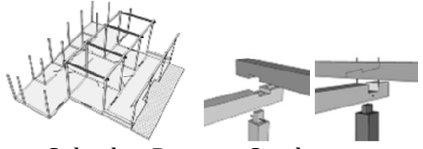

Saka dan Penguat Sambungan

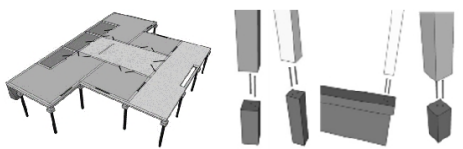

Plat Lantai dan Peninggian Saka

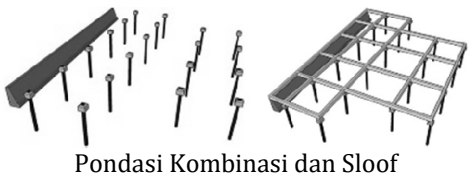

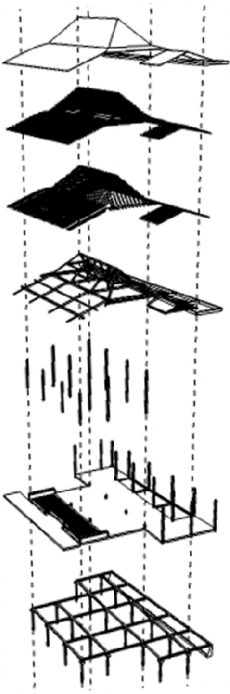

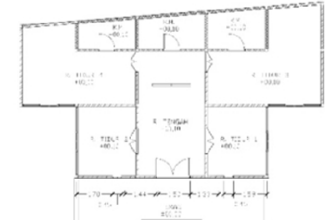

Denah Griva Dorogepak 1
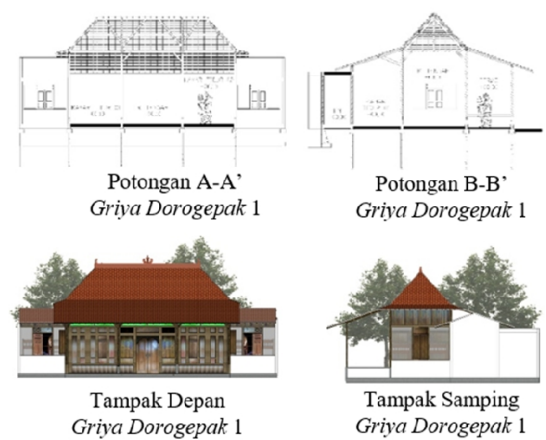

Gambar 4. Griya Dorogepak 1
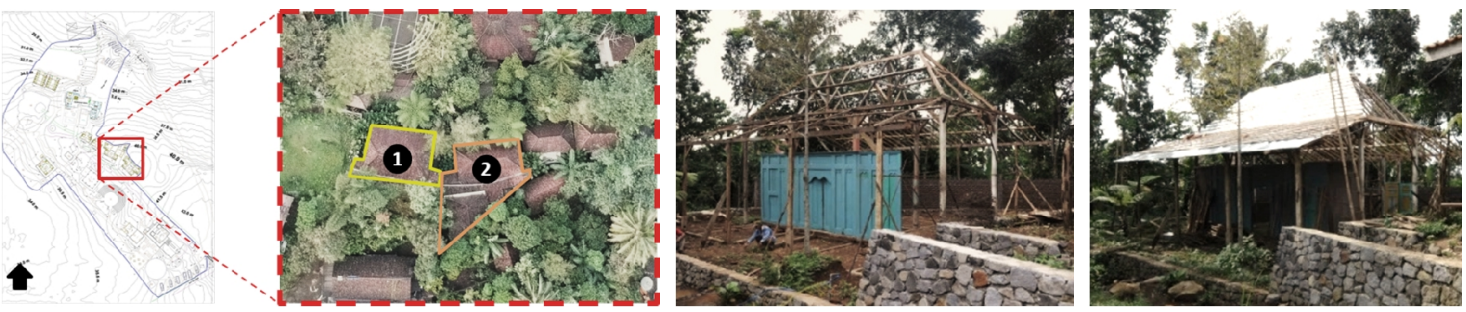

Gambar 5. Translokasi Griya Dorogepak 2
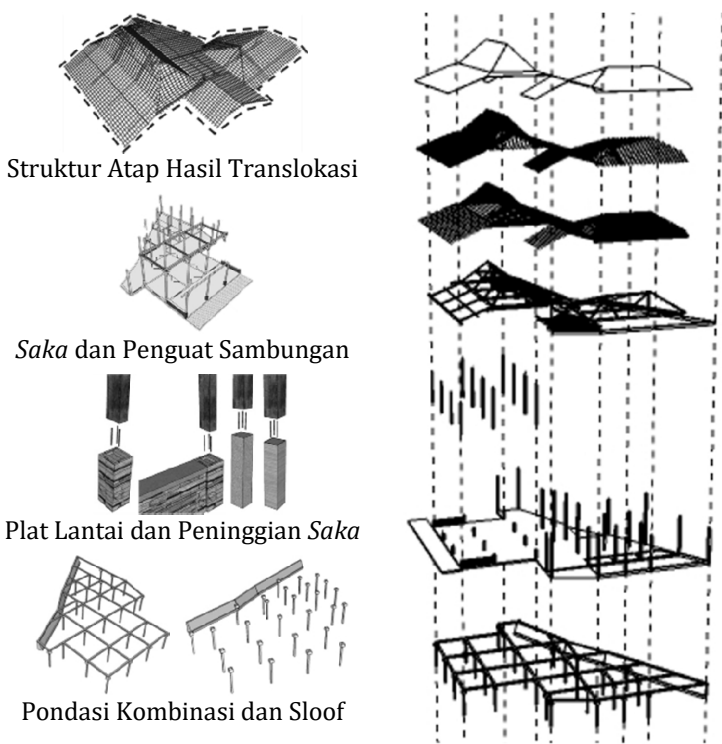

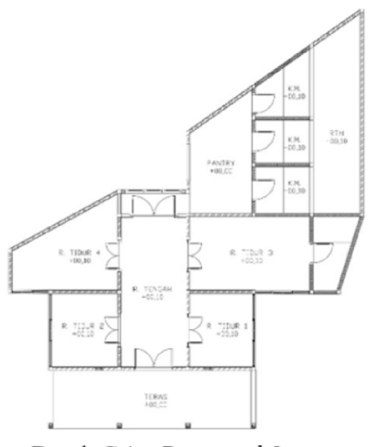

Denah Griya Dorogepak 2
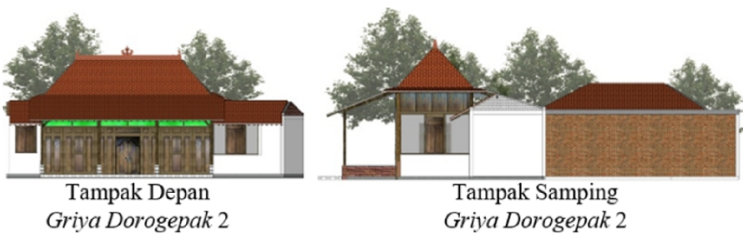

Gambar 6. Griya Dorogepak 2

\subsubsection{Griya Joglo}

Griya Joglo merupakan bangunan vernakular Jawa tipe joglo. Bangunan yang digunakan untuk membangun Griya Joglo berjumlah dua bangunan. Satu bangunan berasal dari Kecamatan Trowulan dengan tipe joglo dan satu bangunan berasal dari 
Kabupaten Mojokerto dengan tipe limasan. Satu bangunan dengan tipe joglo yang didapatkan dari pengepul merupakan bangunan vernakular Jawa Timur yang sudah beralih fungsi menjadi kandang ternak. Adapun satu bangunan lainnya dengan tipe limasan didapatkan langsung dari pemilik sebelumnya merupakan bangunan vernakular yang difungsikan sebagai gudang. Bangunan dengan tipe joglo digunakan sebagai bangunan utama untuk ditranslokasikan, sedangkan bangunan dengan tipe limasan digunakan untuk melengkapi bagian yang rusak dari bangunan utama. Secara umum struktur utama dari kedua bangunan utama yang akan dibangun memiliki struktur yang masih baik, sehingga hanya perlu mengganti beberapa bagian yang rusak.

Perubahan yang terjadi pada Griya Joglo tidak sebanyak perubahan yang terjadi pada Griya Dorogepak. Griya Joglo mengalami penambahan pondasi, penambahan penguat, penggantian penguat, penggantian plafon, penambahan seng, penggantian genteng dan penambahan beberapa struktur beton. Penambahan struktur beton dikarenakan terdapat penambahan ruang pada Griya Joglo, yaitu penambahan dapur kering dan kamar mandi.
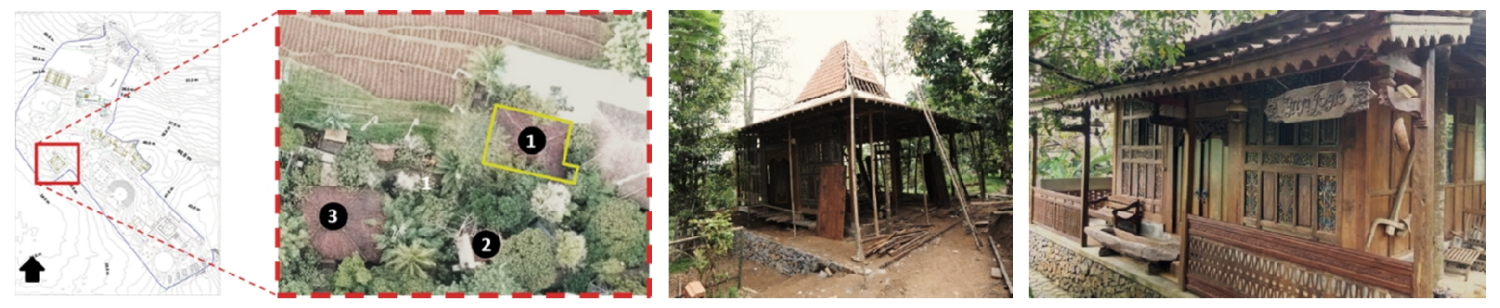

Gambar 7. Translokasi Griya Joglo
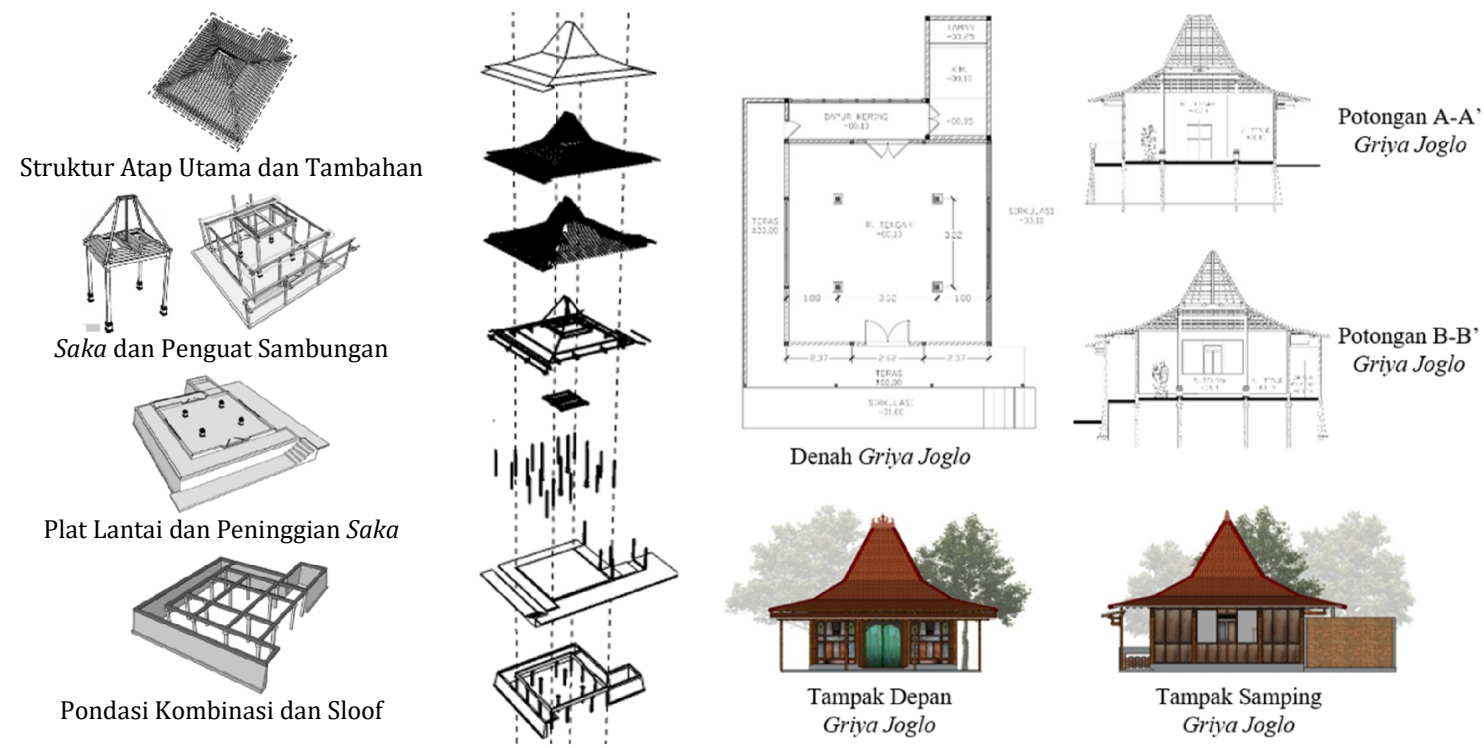

Gambar 8. Griya Joglo

\subsubsection{Griya Jineman}

Griya Jineman merupakan bangunan vernakular Jawa tipe limasan. Bangunan Griya Jineman 1 dan 2 merupakan bangunan yang serupa, sehingga terlihat seperti bangunan kembar. Bangunan yang digunakan untuk membangun Griya Jineman berjumlah dua bangunan, berasal dari Kabupaten Nganjuk dan didapat secara langsung dari pemilik sebelumnya. Griya Jineman mengalami perubahan yang ekstrim, namun terkonsep sehingga menghasilkan tampilan bangunan yang proporsional. Secara umum 
struktur utama dari kedua bangunan utama yang akan dibangun memiliki struktur yang masih baik, sehingga hanya perlu mengganti beberapa bagian yang rusak.

Perubahan yang jelas terlihat dari kolong bangunan yang ditransformasikan menjadi ruangan baru dengan struktur beton. Di bagian atas struktur beton tersebut diletakkan bangunan vernakular hasil translokasi, sehingga struktur beton terkesan sebagai panggung dari bangunan vernakular. Griya Jineman mengalami penambahan pondasi, penambahan dan penggantian penguat, penggantian plafon, penambahan seng, penggantian genteng dan penambahan beberapa struktur beton. Penambahan struktur beton dikarenakan terdapat penambahan ruang pada Griya Jineman di bagian belakang bangunan, berupa penambahan balkon dan kamar mandi.
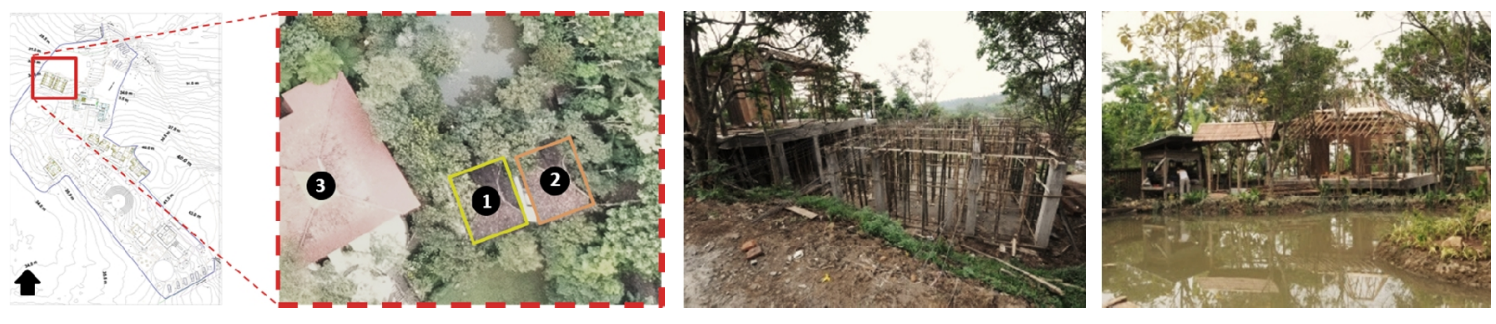

Gambar 9. Translokasi Griya Jineman
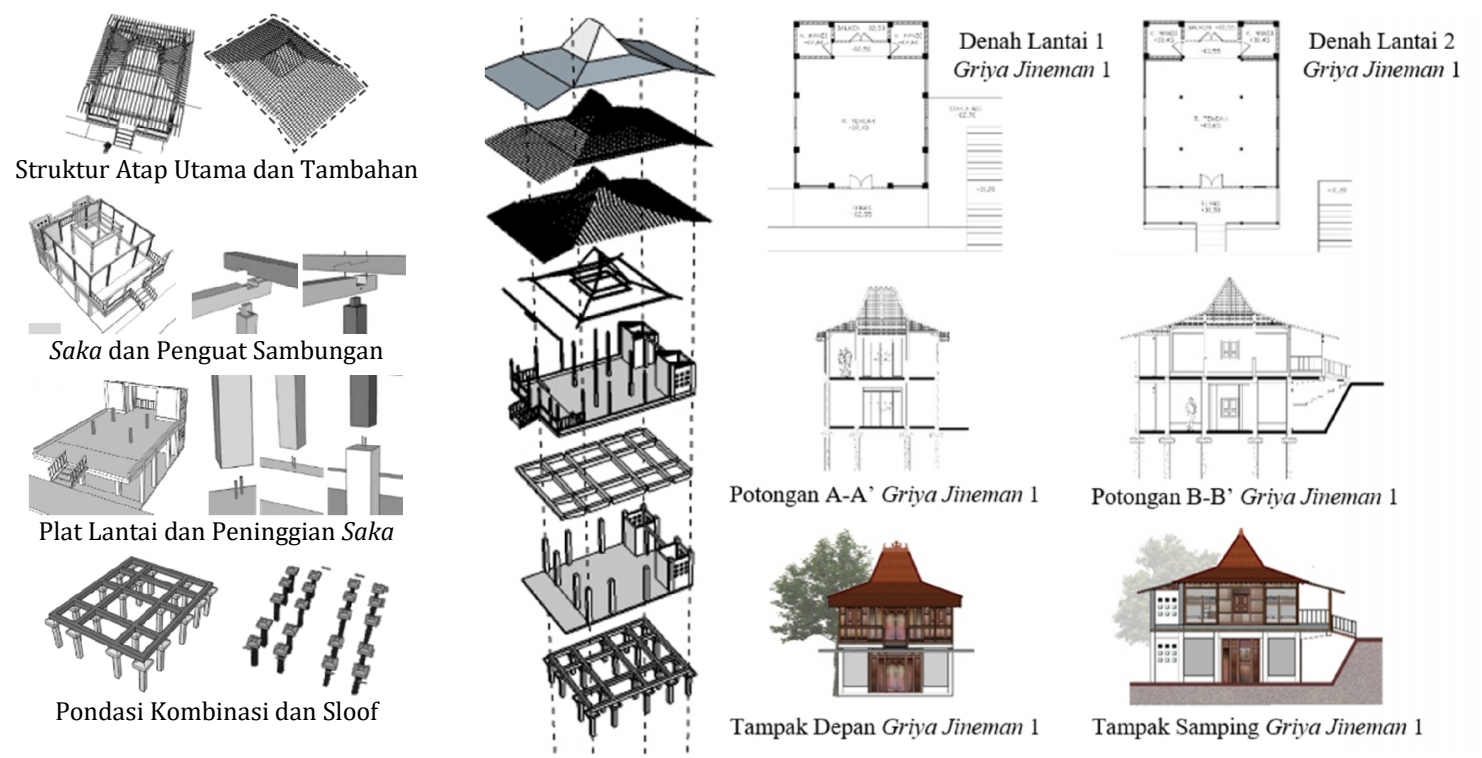

Gambar 10. Griya Jineman

\subsection{Penggunaan Adaptive Reuse}

Konsep yang dikemukakan oleh Scuderi (2015) merupakan metode penyesuaian yang dapat dilakukan apabila pelestarian konvensional (mempertahankan kondisi aslinya) tidak dapat dilakukan. Strategi pelestarian yang dilakukan pada bangunan vernakular Jawa Timur hasil translokasi di Kampoeng Djawi dapat dibagi menjadi dua yaitu penambahan dan pengurangan. Perubahan ini memungkinkan untuk dilakukan mengingat bahwa struktur rumah Jawa sebagian besar terbuat dari kayu yang memiliki umur dan kekuatan yang terbatas. Penyesuaian ini semata-mata dilakukan untuk memperkuat struktur asli sekaligus mewadahi penambahan fungsi barunya (Unakul et al, 2007).

Secara umum perubahan dengan strategi penambahan yang terjadi di Kampoeng Djawi berupa kontinuitas, kontras, penyempurnaan, integrasi dan kontraposisi. 
Penambahan secara kontinuitas terlihat dari penambahan yang menggunakan bentuk dan material yang seirama, bahkan sama dengan aslinya sehingga penambahan yang terjadi diidentifikasi berlanjut. Perubahan kontinuitas terlihat pula pada penambahan atap, peninggi saka, dan fasad tambahan. Penambahan kontras terlihat pada penambahan struktur dan pelingkup baru yang tidak seirama dengan kondisi aslinya. Struktur baru yang digunakan berupa struktur beton dan pelingkup baru yang digunakan berupa batu bata plester. Walaupun terkesan kontras dengan bangunan aslinya, namun pemilik dan tukang dapat membuat komposisi tampilan menjadi lebih estetik. Penambahan dengan penyempurnaan banyak dilakukan di semua bangunan yang ditranslokasikan. Penyempurnaan yang dilakukan berupa penambahan pondasi dan sloof, penambahan seng, peninggi saka dan penyempurnaan agar kayu yang digunakan lebih tahan lama. Penambahan yang terakhir berupa integrasi dan kontraposisi. Penambahan tersebut dapat terlihat dari hasil penambahan ruang pada masing-masing bangunan vernakular hasil translokasi.

Strategi perubahan berikutnya adalah strategi dengan pengurangan. Secara umum perubahan dengan strategi pengurangan yang terjadi di Kampoeng Djawi Wonosalam berupa pembaruan, modifikasi, memotong dan pergantian. Strategi pengurangan dengan pembaruan merupakan strategi awal yang dilakukan untuk mempertahankan bangunan vernakular hasil translokasi. Pembaruan yang dimaksudkan adalah menggantikan bagian yang rusak dengan bagian baru dengan menggunakan bahan dan material yang sama. Bagian yang mengalami pembaharuan diantaranya balok reng, balok usuk, sikuan dan plafon anyaman bambu. Perubahan dengan memodifikasi merupakan perubahan yang banyak dilakukan. Perubahan dengan memodifikasi dapat terlihat dari sambungan antara saka dengan peninggi saka, modifikasi sambungan dan modifikasi penguat. Modifikasi yang jelas terlihat terdapat pada Griya Jineman. Griya Jineman mengalami modifikasi kolong bangunan yang ditransformasi menjadi ruang baru, selain itu juga mengalami modifikasi atap yang awalnya tipe limasan menjadi tipe joglo. Strategi pengurangan berikutnya adalah memotong. Strategi dengan memotong ini terdapat pada Griya Dorogepak. Bagian Griya Dorogepak yang mengalami pemotongan adalah bagian emper karena alasan keterbatasan lahan. Pengurangan yang terakhir adalah dengan melakukan pergantian. Pergantian yang dilakukan adalah mengganti bagian asli yang rusak dengan bagian baru yang lebih kuat ataupun lebih estetis. Pergantian yang dilakukan dapat terlihat pada pergantian saka, sikuan, plafon dan pelingkup atap di masing-masing bangunan vernakular hasil translokasi. 


\section{Tabel 2. Strategi Perubahan pada Rumah Jawa Hasil Translokasi di Kampoeng Djawi}

\begin{tabular}{|c|c|c|c|c|c|}
\hline \multirow{2}{*}{\multicolumn{2}{|c|}{$\begin{array}{c}\text { Strategi } \\
\text { Perubahan }\end{array}$}} & \multicolumn{4}{|c|}{ Rumah Jawa Hasil Translokasi } \\
\hline & & Griya Dorogepak 1 & Griya Dorogepak 2 & Griya Joglo & Griya Jineman \\
\hline \multirow{3}{*}{ 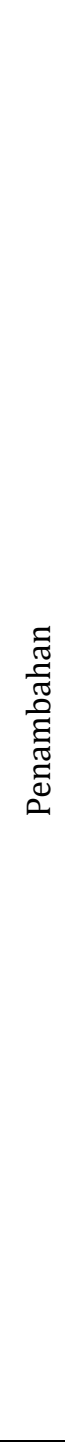 } & 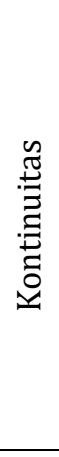 & $\begin{array}{l}\text { - Penggunaan material, warna dan } \\
\text { bentuk yang sama serupa } \\
\text { bangunan aslinya (usuk, reng, } \\
\text { genteng, plafon) } \\
\text { - Penambahan bentuk tetap berpatokan } \\
\text { pada gaya arsitektur Jawa seperti } \\
\text { bentuk sikuan, penambahan atap, } \\
\text { penambahan kolom peninggi } \\
\text { - Penggunaan pelingkup batu bata } \\
\text { plester yang dominan menjadikan } \\
\text { tampilan kontinu }\end{array}$ & $\begin{array}{l}\text { - Penggunaan material, warna dan } \\
\text { bentuk yang sama serupa } \\
\text { bangunan aslinya (usuk, reng, } \\
\text { genteng, plafon) } \\
\text { - Penambahan bentuk tetap } \\
\text { berpatokan pada gaya arsitektur } \\
\text { Jawa seperti bentuk sikuan, } \\
\text { penambahan atap, penambahan } \\
\text { kolom peninggi } \\
\text { - Penggunaan pelingkup batu bata } \\
\text { plester yg dominan }\end{array}$ & $\begin{array}{l}\text { - Penggunaan material dan } \\
\text { warna yang sama dengan } \\
\text { bangunan aslinya seperti } \\
\text { penambahan usuk, reng, } \\
\text { genteng, plafon, pelingkup } \\
\text { bangunan, pintu dan jendela } \\
\text { - Penambahan bentuk tetap } \\
\text { berpatokan pada gaya } \\
\text { arsitektur Jawa seperti bentuk } \\
\text { sikuan, penambahan kolom } \\
\text { peninggi dan umpak batu baru }\end{array}$ & $\begin{array}{l}\text { - Penggunaan material dan warna } \\
\text { yang sama dengan bangunan } \\
\text { aslinya } \\
\text { - Penambahan bentuk tetap } \\
\text { berpatokan pada gaya arsitektur } \\
\text { Jawa seperti bentuk sikuan, } \\
\text { penambahan kolom peninggi } \\
\text { dan umpak batu baru } \\
\text { - Penggunaan pelingkup batu bata } \\
\text { plester yang dominan } \\
\text { menjadikan tampilan kontinu } \\
\end{array}$ \\
\hline & 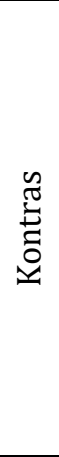 & $\begin{array}{l}\text { - Penggunaan pelingkup yang } \\
\text { didominasi oleh batu bata plester } \\
\text { menjadikan pelingkup kayu berupa } \\
\text { gebyok yang terdapat di bagian } \\
\text { depan bangunan menjadi kontras. } \\
\text { - Penggunaan kuda-kuda gewel } \\
\text { kontras dengan kuda-kuda kayu } \\
\text { yang terekspos } \\
\text { - Penggunaan atap dak beton } \\
\text { kontras dengan struktur atap kayu } \\
\text { yang terekspos }\end{array}$ & $\begin{array}{l}\text { - Penggunaan pelingkup yang } \\
\text { didominasi oleh batu bata plester } \\
\text { menjadikan pelingkup kayu berupa } \\
\text { gebyok yang terdapat di bagian } \\
\text { depan bangunan menjadi kontras. } \\
\text { - Penambahan bangunan tambahan } \\
\text { yang memiliki bentuk denah yang } \\
\text { kontras dengan bangunan asli } \\
\text { - Penggunaan kuda-kuda gewel } \\
\text { kontras dengan kuda-kuda kayu } \\
\text { yang terekspos }\end{array}$ & $\begin{array}{l}\text { - Pengunaan peninggi kolom } \\
\text { dengan finishing plester } \\
\text { - Penambahan ruangan } \\
\text { menggunakan pelingkup bata } \\
\text { merah ekspos }\end{array}$ & $\begin{array}{l}\text { - Penambahan bangunan struktur } \\
\text { beton yang ada di bawahnya } \\
\text { - Penambahan ruangan } \\
\text { menggunakan pelingkup batu } \\
\text { bata plester } \\
\text { - Penggunaan material kaca di sisi } \\
\text { samping bangunan } \\
\text { - Penggunaan pelingkup batu bata } \\
\text { plester yang dominan } \\
\text { menjadikan bangunan asli Griya } \\
\text { Jineman kontras }\end{array}$ \\
\hline & 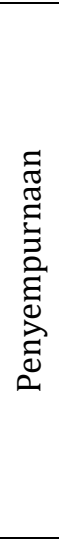 & $\begin{array}{l}\text { - Penggunaan turap di sekitar Griya } \\
\text { Dorogepak } 1 \\
\text { - Penambahan pondasi yang } \\
\text { dihubungkan dengan saka } \\
\text { - Penggunaan sloof dan plat lantai } \\
\text { - Penggunaan peninggi kolom beton } \\
\text { - Menambahkan pelapis seng setelah } \\
\text { pemasangan plafon } \\
\text { - Melapis kayu dengan pernis clear } \\
\text { water-based } \\
\text { - Meletakan } 2 \text { titik makanan rayap di } \\
\text { pekarangan }\end{array}$ & $\begin{array}{l}\text { - Penggunaan turap di sekitar Griya } \\
\text { Dorogepak } 2 \\
\text { - Penambahan pondasi yang } \\
\text { dihubungkan dengan saka } \\
\text { - Penggunaan sloof dan plat lantai } \\
\text { - Penggunaan peninggi kolom beton } \\
\text { menjadikan dimensi bangunan lebih } \\
\text { proporsi } \\
\text { - Menambahkan pelapis seng setelah } \\
\text { pemasangan plafon } \\
\text { - Melapis kayu dengan pernis clear } \\
\text { water-based \& neletakan } 2 \text { titik } \\
\text { makanan rayap di pekarangan }\end{array}$ & $\begin{array}{l}\text { - Penambahan turap \& pondasi } \\
\text { yang dihubungkan dgn saka } \\
\text { - Penggunaan sloof dan plat } \\
\text { lantai } \\
\text { - Penggunaan peninggi kolom } \\
\text { beton menjadikan dimensi } \\
\text { bangunan lebih proporsi } \\
\text { - Menambahkan pelapis seng } \\
\text { setelah pemasangan plafon } \\
\text { - Melapis kayu dengan pernis } \\
\text { clear water-based } \\
\text { - Meletakan } 1 \text { titik makanan } \\
\text { rayap di pekarangan }\end{array}$ & $\begin{array}{l}\text { - Penambahan turap \& pondasi } \\
\text { yang dihubungkan dengan saka } \\
\text { Griya Jineman } \\
\text { - Penggunaan sloof dan plat lantai } \\
\text { - Penggunaan peninggi kolom } \\
\text { beton menjadikan dimensi } \\
\text { bangunan lebih proporsi } \\
\text { - Menambahkan pelapis seng } \\
\text { setelah pemasangan plafon } \\
\text { - Melapis kayu dengan pernis } \\
\text { clear water-based \& } \\
\text { penggunaan makanan rayap } \\
\text { - Merubah atap menjadi tipe joglo }\end{array}$ \\
\hline
\end{tabular}




\begin{tabular}{|c|c|c|c|c|c|}
\hline 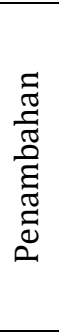 & 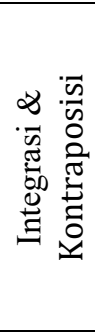 & $\begin{array}{l}\text { - Menghubungkan penambahan kamar } \\
\text { tidur dan kamar mandi dengan } \\
\text { bangunan asli } \\
\text { - Penggunaan atap penambahan ruang } \\
\text { yang terhubung dengan atap } \\
\text { bangunan asli } \\
\text { - Penambahan bagian kanan dan kiri } \\
\text { bangunan yang relatif seimbang }\end{array}$ & $\begin{array}{l}\text { - Penambahan kamar tidur, kamar } \\
\text { mandi dan bangunan tambahan yg } \\
\text { terhubung dengan bangunan asli } \\
\text { - Penggunaan atap penambahan ruang } \\
\text { yang terhubung dengan atap } \\
\text { bangunan asli } \\
\text { - Penambahan bagian kanan dan kiri } \\
\text { bangunan yang relatif seimbang }\end{array}$ & $\begin{array}{l}\text { - Menghubungkan dapur kering } \\
\text { dan kamar mandi dengan } \\
\text { bangunan asli } \\
\text { - Atap penambahan ruang yg } \\
\text { terhubung dgn atap asli } \\
\text { - Penambahan bagian belakang } \\
\text { bangunan dan sekitar } \\
\text { bangunan (emper) }\end{array}$ & $\begin{array}{l}\text { - Menghubungkan penambahan } \\
\text { kamar mandi dgn bangunan asli } \\
\text { - Penggunaan atap penambahan } \\
\text { ruang yang terhubung dengan } \\
\text { atap bangunan asli } \\
\text { - Penambahan bagian belakang } \\
\text { bangunan dan ruangan yang ada } \\
\text { di bawahnya }\end{array}$ \\
\hline \multirow{4}{*}{ 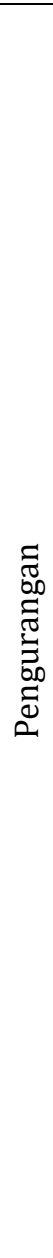 } & 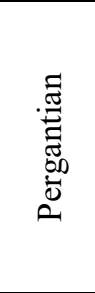 & $\begin{array}{l}\text { - Menganti saka pananggap bagian } \\
\text { belakang dengan kolom beton } \\
\text { - Mengganti beberapa sikuan emper } \\
\text { - Mengganti beberapa pelingkup } \\
\text { dinding kayu dengan batu bata plester } \\
\text { - Mengganti pelingkup atap dengan } \\
\text { genteng press }\end{array}$ & $\begin{array}{l}\text { - Menganti saka pananggap bagian } \\
\text { belakang dengan kolom beton } \\
\text { - Mengganti beberapa sikuan emper, } \\
\text { pelingkup dinding kayu } \\
\text { - Mengganti plafon anyaman bambu } \\
\text { dengan papan jati } \\
\text { - Mengganti atap dgn genteng press }\end{array}$ & $\begin{array}{l}\text { - Mengganti semua sikuan } \\
\text { emper } \\
\text { - Mengganti plafon dengan } \\
\text { papan jati } \\
\text { - Mengganti pelingkup atap } \\
\text { dengan genteng press }\end{array}$ & $\begin{array}{l}\text { - Mengganti beberapa sikuan } \\
\text { emper } \\
\text { - Mengganti beberapa saka emper } \\
\text { - Mengganti plafon dengan papan } \\
\text { jati } \\
\text { - Mengganti pelingkup atap } \\
\text { dengan genteng press }\end{array}$ \\
\hline & 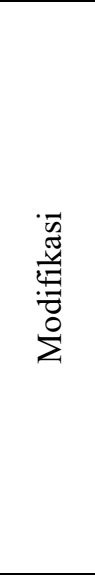 & $\begin{array}{l}\text { - Modifikasi saka agar dapat terhubung } \\
\text { dengan kolom beton peninggi } \\
\text { - Modifikasi beberapa sambungan antar } \\
\text { kayu pada blandar dengan } \\
\text { menggunakan baut dan mur } \\
\text { - Modifikasi blandar pananggap } \\
\text { bagian belakang dengan pengunci } \\
\text { tulangan besi } \\
\text { - Modifikasi saka pananggap bagian } \\
\text { belakang agar strukturnya dapat } \\
\text { berintegrasi dengan struktur } \\
\text { penambahan ruang } \\
\text { - Modifikasi penguat sikuan di bagian } \\
\text { emper dengan menggunakan paku }\end{array}$ & $\begin{array}{l}\text { - Modifikasi saka dengan kolom } \\
\text { beton peninggi } \\
\text { - Modifikasi beberapa sambungan } \\
\text { antar kayu pada blandar dengan } \\
\text { menggunakan baut dan mur } \\
\text { - Modifikasi blandar pananggap } \\
\text { bagian belakang dengan pengunci } \\
\text { tulangan besi } \\
\text { - Modifikasi saka pananggap bagian } \\
\text { belakang agar strukturnya dapat } \\
\text { berintegrasi dengan struktur } \\
\text { penambahan ruang } \\
\text { - Modifikasi penguat sikuan di bagian } \\
\text { emper dengan menggunakan paku }\end{array}$ & $\begin{array}{l}\text { - Modifikasi sambungan dan } \\
\text { ukuran kayu } \\
\text { - Modifikasi saka agar dapat } \\
\text { terhubung dengan kolom beton } \\
\text { peninggi } \\
\text { - Modifikasi beberapa } \\
\text { sambungan antar kayu pada } \\
\text { blandar dengan menggunakan } \\
\text { baut dan mur } \\
\text { - Modifikasi penguat sikuan di } \\
\text { bagian emper dengan } \\
\text { menggunakan paku }\end{array}$ & $\begin{array}{l}\text { - Modifikasi saka agar dapat } \\
\text { terhubung dengan kolom beton } \\
\text { peninggi } \\
\text { - Modifikasi beberapa sambungan } \\
\text { antar kayu pada blandar dengan } \\
\text { menggunakan baut dan mur } \\
\text { - Modifikasi penguat sikuan di } \\
\text { bagian emper dengan } \\
\text { menggunakan paku } \\
\text { - Modifikasi bentuk atap limasan } \\
\text { menjadi joglo }\end{array}$ \\
\hline & $\begin{array}{l}\infty 00 \\
0 \\
0 \\
0 \\
0 \\
0 \\
\sum\end{array}$ & $\begin{array}{l}\text { - Memotong (mengghilangkan) bagian } \\
\text { emper asli }\end{array}$ & $\begin{array}{l}\text { - Memotong (mengghilangkan) } \\
\text { bagian emper asli }\end{array}$ & - & - \\
\hline & 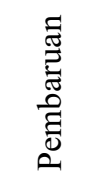 & $\begin{array}{l}\text { - Pembaruan sikuan, usuk, reng, pasak } \\
\text { kayu dan anyaman bambu }\end{array}$ & - Pembaruan sikuan, usuk dan reng & - Pembaruan usuk dan reng & - Pembaruan usuk dan reng \\
\hline
\end{tabular}




\section{Kesimpulan}

Berdasarkan hasil analisa sebelumnya, translokasi bangunan vernakular Jawa Timur di Kampoeng Djawi Wonosalam merupakan bentuk pendekatan pelestarian secara eks-situ dengan penggunaan adaptive reuse. Adaptive reuse yang dimaksud adalah menggunakan kembali bangunan vernakular yang mulai ditinggalkan untuk dimodifikasi dan disesuaikan untuk fungsi baru. Bangunan vernakular Jawa Timur yang sudah ditinggalkan kembali digunakan dan difungsikan, salah satunya menjadi tempat penginapan. Pengaruh penggunaan bangunan sebagai destinasi wisata terlihat dari penyesuaian dengan struktur baru dan beberapa modifikasi untuk menambahkan daya tampung bangunan.

Kondisi yang memperihatinkan dari rumah Jawa hasil translokasi menuntut beberapa penyesuaian dan perubahan. Perubahan ini dilakukan sebagai tanggapan bangunan terhadap lingkungan dan fungsi barunya. Secara umum perubahan yang terjadi antara bangunan yang satu dengan yang lain memiliki kesamaan. Pada struktur bangunan hasil translokasi di Kampoeng Djawi Wonosalam, penyesuaian dilakukan dengan mempertibangkan tiga faktor, yaitu faktor kemananan dan ketahanan, faktor pemenuhan fungsi baru dan faktor memperindah tampilan visual.

Faktor keamanan dan ketahanan disebabkan karena lokasi baru bangunan menuntut penyesuaian dan modifikasi pada struktur asli agar bangunan semakin kokoh. Faktor tersebut menyebabkan perubahan struktur berupa penguatan struktur di beberapa bagian, penambahan struktur baru untuk memperkuat bangunan, hingga penyesuaian material untuk menjaga ketahanan bangunan. Faktor berikutnya adalah pemenuhan fungsi baru. Faktor tersebut disebabkan karena adanya aktivitas baru yang diwadahi, sehingga perlu adanya penyesuaian luasan dan jumlah ruang. Konsekuensinya, penyesuaian ini menyebabkan berubahnya struktur asli. Faktor yang terakhir adalah faktor visual. Faktor ini menuntut tampilan visual bangunan hasil translokasi agar semakin menarik karena diperuntukkan sebagai penunjang fungsi penginapan sekaligus destinasi wisata.

\section{Daftar Pustaka}

Ismunandar. 2003. Joglo Arsitektur Rumah Tradisional Jawa. Semarang: Effhar.

Rapoport, A. 1969. House Form and Culture. United States of America: Prentice-Hall. Prijotomo, Josef. 2005. Pengkonstruksian Sektor Guru Dari Griya Jawa: Tafsir Atas Kawruh Kalang. Dimensi Teknik Arsitektur. 33 (I): 95 - 111.

Scuderi, Giuliana. 2015. Adaptive Building Exoskeletons A Biomimetic Model for the Rehabilitation of Social Housing. Archnet-IJAR, Volume 9 - Issue 1: 134-143.

Unakul, Montira H., et al. 2007. The Homeowner's Conservation Manual for Kotagede Heritage District. Jakarta: Unesco House.

Yusran, Y. A. 2018. Envisioning Open-Air Museum for Indonesian. Dimensi: Journal of Architecture and Building Enviroment, vol. 45, no. 1, pp. 63-72. 